\title{
QUALIDADE FISIOLÓGICA DE SEMENTES DE TOMATE EM FUNÇÃO DAIDADE E DO ARMAZENAMENTO PÓS-COLHEITA DOS FRUTOS ${ }^{1}$
}

\author{
DEBORAHDE SOUZA VIDIGAL ${ }^{2}$, DENISE CUNHAFERNANDES DOS SANTOS DIAS ${ }^{3}$, DANIEL DOS SANTOS PORTO CARRERO NAVEIRA², \\ FABIANO BRANCOROCHA ${ }^{4}$, MARIACARMEN BHERING $^{5}$
}

\begin{abstract}
RESUMO - O trabalho teve como objetivo verificar os efeitos da idade e do período de armazenamento pós-colheita dos frutos de tomate, variedade Kadá, grupo Santa Cruz, sobre a qualidade das sementes. Os frutos foram colhidos aos 40, 50 e 60 dias (DAA) e armazenados por 0 , 4, 8 e 12 dias antes da extração das sementes. Estas foram colocadas para fermentar por dois dias a $25^{\circ} \mathrm{C}$, para retirada da mucilagem. Foram avaliadas as seguintes características: grau de umidade e conteúdo de matéria seca das sementes, germinação, primeira contagem de germinação, índice de velocidade de emergência, envelhecimento acelerado e condutividade elétrica. $\mathrm{O}$ armazenamento pós-colheita dos frutos colhidos aos 60 DAA não favorece a qualidade das sementes. Já para frutos colhidos aos $50 \mathrm{DAA}$, o armazenamento por 8 dias é favorável à velocidade de emergência. Colheitas precoces (40 DAA) só são benéficas à qualidade fisiológica das sementes quando associadas a um período de armazenamento pós-colheita dos frutos de 12 dias.
\end{abstract}

Termos para indexação: Lycopersicon esculentum, vigor, maturação.

\section{PHYSIOLOGICAL QUALITY OF TOMATO SEEDS IN RELATION TO FRUIT AGEAND POST- HARVEST STORAGE}

\begin{abstract}
The objective of this study was to evaluate the effects of age and post-harvest storage period of tomato fruits (Kada cv, Santa Cruz group) on seed quality. Fruits were harvested at 40, 50 and $60 \mathrm{DAA}$ and stored for $0,4,8$ and 12 days before seed extraction. The seeds were fermented for two days at $25^{\circ} \mathrm{C}$ to remove the mucilage. The following characteristics were evaluated: seed moisture and dry matter content, standard germination, first count, speed emergence index, accelerated aging and electrical conductivity. The post-harvest storage of fruits harvested at 60 DAA reduced the seed quality. For the fruits harvested at 50 DAA, 8 days-storage contributed to increasing the speed of emergence. Early harvest (40 DAA) was beneficial to physiological seed quality, when related to post harvest fruit storage for 12 days.
\end{abstract}

Index terms: Lycopersicon esculentum, vigor, maturation.

\section{INTRODUÇÃO}

As sementes se desenvolvem a partir de óvulos fertilizados, que passam por uma série de transformações morfológicas, fisiológicas e funcionais até que a maturidade fisiológica seja atingida, quando cessa a translocação de assimilados da planta para a semente. Neste ponto, o conteúdo de matéria seca da semente é máximo (Carvalho e Nakagawa,

\footnotetext{
${ }^{1}$ Submetido em 03/05/2005. Aceito para publicação em 07/06/2005;

${ }^{2}$ Estudante de Graduação, Departamento de Fitotecnia, Universidade Federal de Viçosa, CEP: 36570-000, Viçosa - MG, deborahvidigal@yahoo.com.br;

${ }^{3}$ Professor Adjunto, Departamento de Fitotecnia, Universidade Federal de Viçosa, CEP: 36570-000, Viçosa-MG, dcdias@ufv.br;
}

2000). Contudo, a semente pode ou não ter atingido os valores máximos de germinação e vigor. Segundo Demir e Ellis (1992), para algumas espécies, a qualidade máxima da semente é obtida simultaneamente ao ponto em que a matéria seca é máxima, enquanto que para outras pode ser verificado antes ou após tal ponto. Uma vez atingida a qualidade máxima, iniciase o processo de deterioração, provocando redução gradativa da qualidade fisiológica da semente (Carvalho e Nakagawa,

${ }^{4}$ Estudante de Pós-graduação, Departamento de Fitopatologia, Universidade Federal de Viçosa, CEP: 36570-000, Viçosa - MG, rochafb@gmail.com;

${ }^{5}$ Pesquisadora, M.Sc., Departamento de Fitotecnia, Universidade Federal de Viçosa, CEP: 36570-000, Viçosa - MG, mbhering@ufv.br. 
2000). Assim, um aspecto importante da produção de sementes é a determinação da maturidade fisiológica e do momento ideal de colheita, visando obter sementes de alta qualidade, minimizando sua deterioração no campo.

Para espécies de frutos carnosos, como as solanáceas e cucurbitáceas, o processo de maturação das sementes continua após a colheita dos frutos. Este aspecto é vantajoso, pois permite colher os frutos precocemente, submetendo-os a um período de armazenamento ou repouso pós-colheita suficiente para que as sementes atinjam a qualidade máxima. Em espécies com hábito de crescimento indeterminado, como o tomate, onde o florescimento é contínuo e de grande desuniformidade nos estádios de maturação dos frutos por ocasião da colheita, um menor número de colheitas poderia ser realizado, colhendose frutos em diferentes estádios de maturação, extraindo-se as sementes dos frutos maduros e submetendo-se os demais a períodos variáveis de armazenamento pós-colheita. A colheita precoce dos frutos ainda teria como vantagem diminuir sua exposição às intempéries e aos ataques de pragas e microorganismos no campo (Barbedo et al., 1994b).

Diversos trabalhos têm comprovado o efeito positivo do armazenamento pós-colheita dos frutos na melhoria da qualidade das sementes, sendo este efeito mais evidente quando os frutos são colhidos precocemente, antes da completa maturação (Araújo et al., 1982; Alvarenga et al., 1984; Alvarenga et al., 1991). Barbedo et al. (1994a) também verificaram que sementes de berinjela de melhor qualidade foram obtidas de frutos com 50 dias de idade submetidos a 15 dias de armazenamento pós-colheita, o que não se repetiu quando o repouso foi realizado em frutos colhidos aos 70 dias após a antese (DAA). Em pepino, a qualidade fisiológica das sementes obtidas de frutos colhidos mais jovens (20, 25 e 30 DAA) e armazenados após a colheita foi similar à de sementes extraídas de frutos colhidos aos 40 e 45 DAA, não armazenados (Barbedo et al., 1994b). Resultados obtidos por Sanchez et al. (1993) indicaram que sementes de pimentão devem permanecer no fruto maduro (idade de 50 DAA) após a colheita, por curto período de tempo, para que o potencial máximo de germinação seja atingido.

Para tomate, são escassas as informações sobre os efeitos do armazenamento pós-colheita dos frutos na qualidade das sementes. Alguns trabalhos têm mostrado aumentos significativos na qualidade fisiológica das sementes durante $\mathrm{o}$ desenvolvimento do fruto, sendo mais pronunciada com a mudança de coloração do fruto de verde para vermelho (Kwon e Bradford, 1987; Demir e Ellis, 1992; Valdes e Gray, 1998; Pereira, 2004). Segundo Valdes e Gray (1998), a germinação das sementes foi máxima em frutos com coloração externa ainda verde, mas com coloração interna já avermelhada, permanecendo elevada até o estádio completamente maduro; contudo, maior velocidade de germinação foi observada nas sementes extraídas de frutos colhidos maduros (completamente vermelhos). O atraso na colheita (frutos colhidos super maduros) levou à deterioração das sementes. Resultados semelhantes foram obtidos por Pereira (2004), que constatou qualidade físiológica máxima para as sementes obtidas de frutos colhidos aos 70 DAA, ocasião em que a maioria dos frutos apresentava $90 \%$ do pericarpo vermelho. Este autor verificou, ainda, que frutos de tomate colhidos em início de amadurecimento e armazenados até estarem completamente maduros produzem sementes de melhor qualidade.

O trabalho teve como objetivo avaliar a influência da idade e do armazenamento pós-colheita dos frutos na qualidade fisiológica de sementes de tomate.

\section{MATERIAL E MÉTODOS}

O campo de produção das sementes foi instalado na Horta Nova do Departamento de Fitotecnia, Universidade Federal de Viçosa - UFV, no período de março a julho de 2004. Foram utilizadas sementes de tomate, variedade Kadá, Grupo Santa Cruz. Após a semeadura e obtenção das mudas em viveiro, estas foram transplantadas para o local definitivo, no espaçamento de 1,0x0,5m. A condução da cultura seguiu as recomendações usuais para tomate tutorado (Fontes, 2005) com irrigações realizadas em sulcos abertos nas entrelinhas da cultura.

Durante o ciclo da cultura, as flores foram etiquetadas no dia de sua antese. As colheitas foram realizadas aos 40, 50 e 60 dias após a antese (DAA). Os frutos colhidos em cada época foram mantidos em repouso por $0,4,8$ e 12 dias, em galpão, sob condições ambientais. Após cada período de repouso, as sementes foram removidas dos frutos, sendo submetidas à fermentação, por dois dias, em condições de ambiente, com temperatura em torno de $25^{\circ} \mathrm{C}$. Ao final deste processo, a mucilagem foi totalmente removida por meio de lavagem em água corrente.

$\mathrm{Na}$ seqüência, as sementes foram colocadas para secar sobre papel toalha, em laboratório, sob temperatura em torno de $20^{\circ} \mathrm{C}$, por aproximadamente dois dias, até atingirem grau de umidade compatível com o armazenamento, cerca de $10 \%$. Após a secagem, as sementes foram tratadas com o fungicida Captan, na dosagem de 2,0g i.a./kg de sementes. Apenas as 
sementes destinadas à realização do teste de condutividade elétrica não foram tratadas com fungicida. Em seguida, foram submetidas aos seguintes testes e determinações: Grau de umidade - determinado conforme metodologia prescrita nas Regras para Análise de Sementes (Brasil, 1992), pelo método da secagem em estufa a $105 \pm 3{ }^{\circ} \mathrm{C}$, durante 24 horas, utilizando-se três repetições. Os resultados foram expressos em porcentagem (bu). Peso da matéria seca da semente determinado em 3 repetições de 50 sementes com base no peso final das sementes após secagem a $105 \pm 3^{\circ} \mathrm{C}$ por $24 \mathrm{~h}$ (Brasil, 1992). Os resultados foram expressos em mg.semente ${ }^{-1}$. Teste de germinação - conduzido com quatro repetições de 50 sementes distribuídas sobre duas folhas de papel germitest umedecidas com água (volume equivalente a 2,5 vezes o peso do papel seco), em caixas de gerbox. As caixas foram colocadas em germinador a $25^{\circ} \mathrm{C}$. As avaliações foram feitas no sétimo e décimo quarto dia após a semeadura e os resultados expressos em porcentagem de plântulas normais. Primeira contagem de germinação - consistiu do registro da porcentagem de plântulas normais, obtidas no sétimo dia após a montagem do teste (Brasil, 1992). Índice de velocidade de emergência de plântulas - quatro repetições de 25 sementes foram semeadas a $3 \mathrm{~mm}$ de profundidade, em bandejas plásticas contendo areia umedecida $(70 \%$ da capacidade de retenção). As bandejas foram mantidas em laboratório, a $25^{\circ} \mathrm{C}$. Foram feitas contagens diárias do número de plântulas emergidas até o $15^{\circ}$ dia, calculando-se o Índice de Velocidade de Emergência (IVE) conforme Maguire (1962). Envelhecimento acelerado - inicialmente, 300 sementes foram distribuídas uniformemente sobre tela acoplada ao gerbox, com $40 \mathrm{~mL}$ de água. Os gerbox foram tampados e mantidos em câmara BOD, a $41^{\circ} \mathrm{C}$ por $72 \mathrm{~h}$. Decorrido este período, duas repetições de 50 sementes foram utilizadas para determinação do grau de umidade das sementes, pelo método da estufa a $105 \pm 3^{\circ} \mathrm{C}$ por $24 \mathrm{~h}$ e 4 repetições de 50 sementes foram submetidas ao teste de germinação, conforme descrito acima. Os resultados foram expressos em porcentagem de plântulas normais obtidas aos sete dias após a semeadura. Condutividade elétrica - foram empregadas quatro repetições de 50 sementes, com massas conhecidas, colocadas para embebição em copos plásticos contendo $50 \mathrm{~mL}$ de água destilada e mantidos em incubadora BOD a $25^{\circ} \mathrm{C}$ por 24 horas (Panobianco, 2000). Após esse período, procedeu-se à leitura em um condutivímetro, e os resultados foram expressos em $\mathrm{mS} . \mathrm{cm}^{-1} \cdot \mathrm{g}^{-1}$ de sementes.

Procedimento estatístico - $\mathrm{O}$ delineamento utilizado foi o inteiramente casualizado, com 12 tratamentos constituídos pela combinação de três idades de frutos $(40,50$ e 60 DAA) e quatro períodos de armazenamento pós-colheita $(0,4,8$ e 12 dias), com quatro repetições. Os dados foram submetidos à análise de variância e para a comparação de médias foi utilizado o teste de Tukey a 5\% de probabilidade.

\section{RESULTADOS E DISCUSSÃO}

Pela Tabela 1, verifica-se que o grau de umidade das sementes de frutos colhidos aos 40 DAA foi, em geral, superior ao obtido para as sementes de frutos colhidos aos 50 e 60 DAA. Sementes extraídas de frutos submetidos ao armazenamento pós-colheita por 8 e 12 dias tiveram redução no grau de umidade com o aumento da idade do fruto, enquanto que nos frutos armazenados por 4 dias, menor teor

TABELA 1. Grau de umidade (\%) e conteúdo de matéria seca (mg.semente-1) de sementes de tomate, em função da idade (40, 50 e 60 DAA) e período de armazenamento pós-colheita ( $0,4,8$ e 12 dias) dos frutos.

\begin{tabular}{|c|c|c|c|c|}
\hline \multirow{3}{*}{$\begin{array}{l}\text { Idade dos frutos (dias } \\
\text { após antese - DAA) }\end{array}$} & \multicolumn{4}{|c|}{ Período de armazenamento pós-colheita (dias) } \\
\hline & 0 & 4 & 8 & 12 \\
\hline & \multicolumn{4}{|c|}{ Grau de Umidade (\%) } \\
\hline 40 & $83,6 \mathrm{Aa}$ & $81,4 \mathrm{ABa}$ & $79,0 \mathrm{Ba}$ & $79,0 \mathrm{Ba}$ \\
\hline 50 & $74,0 \mathrm{Bb}$ & $73,6 \mathrm{Bc}$ & $77,8 \mathrm{Aa}$ & $75,5 \mathrm{ABc}$ \\
\hline 60 & $75,0 \mathrm{ABb}$ & $76,4 \mathrm{Ab}$ & $73,5 \mathrm{Bb}$ & $72,9 \mathrm{Bc}$ \\
\hline \multicolumn{5}{|l|}{ C.V. $(\%)=1,05$} \\
\hline & \multicolumn{4}{|c|}{ Conteúdo de matéria seca (mg.semente $^{-1}$ ) } \\
\hline 40 & $2,76 \mathrm{Cb}$ & $3,22 \mathrm{ABc}$ & $3,01 \mathrm{Bc}$ & $3,39 \mathrm{Ab}$ \\
\hline 50 & $3,68 \mathrm{Ba}$ & $3,70 \mathrm{Ba}$ & $3,71 \mathrm{ABa}$ & $3,05 \mathrm{Aa}$ \\
\hline 60 & $3,56 \mathrm{Aa}$ & $3,25 \mathrm{Bb}$ & $3,29 \mathrm{Bb}$ & $3,11 \mathrm{Bc}$ \\
\hline
\end{tabular}

Médias seguidas da mesma letra, maiúscula na linha e minúscula na coluna, não diferem entre si, pelo teste de Tukey a 5\% de probabilidade. 
de água foi verificado para as sementes com idade de 50 DAA $(73,6 \%)$. Verificou-se ainda que com o aumento do período de repouso dos frutos, houve tendência de redução no grau de umidade das sementes, para as idades de 40 e 60 DAA, o que não ocorreu aos $50 \mathrm{DAA}$, onde os valores variaram $73,6 \%$ (4 dias de repouso) a $77,9 \%$ (8 dias de repouso).Decréscimo no teor de água das sementes com o armazenamento dos frutos foi constatado por Barbedo et al. (1993), em pepino. Em melancia, o grau de umidade das sementes provenientes de frutos mais novos (35 dias de idade) decresceu com o aumento do período de armazenamento dos frutos; nas sementes provenientes de frutos com 55 dias de idade ocorreu reabsorção de água após 4 dias de armazenamento pós-colheita (Alvarenga et al., 1984). Demir e Ellis (1992) verificaram que o grau de umidade das sementes de tomate durante o desenvolvimento variou de 53 a $72 \%$, atingindo $53 \%$ no momento da colheita. Na maturidade fisiológica (frutos com 20-25\% do pericarpo vermelho), o grau de umidade foi de 61 a $72 \%$. Valdes e Gray (1998) verificaram que o teor de água das sementes de tomate praticamente não alterou com o amadurecimento dos frutos, ao contrário do que foi relatado por Berry e Bewley (1991).

O conteúdo de matéria seca das sementes foi maior aos 50 e 60 DAA, apenas nos frutos não armazenados. Nos frutos armazenados por 4, 8 e 12 dias, maior conteúdo de matéria seca ocorreu aos 50 DAA, declinando aos 60 DAA (Tabela 1). Com armazenamento dos frutos colhidos aos $40 \mathrm{DAA}$ houve aumento na matéria seca das sementes, com maior valor aos 12 dias de armazenamento, tendência esta que se manteve nos frutos com 50 DAA de idade. Já aos 60 DAA, verificou-se comportamento inverso, ou seja, o armazenamento pós-colheita dos frutos provocou redução no conteúdo de matéria seca das sementes, uma vez que o maior valor foi obtido para as sementes de frutos não armazenados. Provavelmente, o decréscimo foi acarretado por possível aumento na taxa de respiração dessas sementes. Em sementes de pepino, Barbedo et al. (1994b) verificaram que o conteúdo de matéria seca não apresentou tendências evidentes com o repouso dos frutos. Em sementes de pimentão, Sanchez et al. (1993) não constataram diferenças significativas no peso de matéria seca das sementes extraídas de frutos submetidos ou não ao armazenamento pós-colheita. Em sementes de abóbora italiana, houve aumento na matéria seca das sementes com o aumento da idade dos frutos até aos 65 DAA, no tratamento sem armazenamento (Alvarenga et al., 1991). Estes autores verificaram que, quando foi feito o armazenamento dos frutos mais novos (25 DAA), o aumento do conteúdo de matéria das sementes foi evidente, indicando que o fluxo de nutrientes do fruto para a semente não cessou após sua colheita, uma vez que as sementes provenientes destes frutos armazenados por apenas três dias, apresentaram o dobro do peso de matéria seca quando comparadas àquelas extraídas de frutos não armazenados.

A germinação das sementes foi crescente com o armazenamento dos frutos colhidos aos 40 DAA, sendo nula nos frutos sem repouso e atingindo $97,5 \%$ com o armazenamento por 12 dias (Tabela 2). Por outro lado, aos 50 e 60 DAA não houve aumento na germinação das sementes com o armazenamento dos frutos. Contudo, pode-se constatar para a idade de 60 DAA, pelos valores absolutos, a redução na germinação com o armazenamento dos frutos, o que pode ser atribuído ao início do processo de deterioração das sementes após terem adquirido capacidade máxima de germinação. Portanto, o armazenamento pós-colheita dos frutos mostrouse benéfico para a germinação das sementes apenas quando os frutos foram colhidos aos 40 DAA. O efeito positivo do armazenamento dos frutos de melão, colhidos aos 30 e 50 DAA, na germinação das sementes foi atribuído por Welbaum e Bradford (1991) a um possível priming realizado 'in situ'. De fato, dentro do fruto maduro, o potencial osmótico é suficientemente baixo para, além de evitar a germinação precoce das sementes, promover efeito similar ao do condicionamento osmótico. De acordo com Welbaum e Bradford (1991), o potencial hídrico no interior dos frutos de melão durante a maturação é de, aproximadamente, $-1,3 \mathrm{MPa}$, sendo similar aos potenciais tradicionalmente utilizados para o condicionamento osmótico das sementes.

Nos frutos não submetidos ao armazenamento (Tabela 2), só houve germinação expressiva a partir dos 50 DAA que não diferiu de 60 DAA, o que também foi constatado para frutos armazenados por quatro dias. Já nos frutos armazenados por 8 dias, maior porcentagem de germinação ocorreu quando a colheita foi realizada aos 50 DAA, enquanto que menor germinação foi observada aos 40 DAA. Quando os frutos foram armazenados por 12 dias, maior germinação foi observada aos 40 e 50 DAA, embora os valores obtidos aos 50 DAA (93\%) e 60 DAA (78\%) não tenham diferido significativamente. Esses resultados corroboram informações obtidas por Sanchez et al. (1993), onde sementes de pimentão extraídas de frutos verdes (30 DAA) não germinaram, enquanto que aquelas obtidas de frutos vermelhos maduros e super maduros (50 e $60 \mathrm{DAA}$, respectivamente) tiveram germinação significativamente superior em relação às sementes extraídas de frutos colhidos aos 40 DAA. Nesses, a 
TABELA2. Plântulas normais (\%) obtidas nos testes de germinação, primeira contagem de germinação e envelhecimento acelerado, índice de velocidade de emergência (IVE) e condutividade elétrica $\left(\mu \mathrm{S} . \mathrm{cm}^{-1} \cdot \mathrm{g}^{-1}\right)$ de sementes de tomate, em função da idade $(40,50$ e 60 DAA) e período de armazenamento pós-colheita $(0,4,8$ e 12 dias) dos frutos.

\begin{tabular}{|c|c|c|c|c|}
\hline \multirow{3}{*}{$\begin{array}{l}\text { Idade dos Frutos (Dias } \\
\text { após antese - DAA) }\end{array}$} & \multicolumn{4}{|c|}{ Período de armazenamento pós-colheita (dias) } \\
\hline & 0 & 4 & 8 & 12 \\
\hline & \multicolumn{4}{|c|}{ Germinação (\%) } \\
\hline 40 & $0,0 \mathrm{Cb}$ & $7,5 \mathrm{Cb}$ & $46,0 \mathrm{Bc}$ & $97,5 \mathrm{Aa}$ \\
\hline 50 & $83,5 \mathrm{Aa}$ & $90,0 \mathrm{Aa}$ & $99,5 \mathrm{Aa}$ & $93,0 \mathrm{Aab}$ \\
\hline 60 & $93,5 \mathrm{Aa}$ & $95,5 \mathrm{Aa}$ & $80,5 \mathrm{Ab}$ & $77,5 \mathrm{Ab}$ \\
\hline \multicolumn{5}{|l|}{ C.V. $(\%)=13,85$} \\
\hline \multicolumn{5}{|c|}{ Primeira contagem de germinação (\%) } \\
\hline 40 & $0,0 \mathrm{Cb}$ & $2,0 \mathrm{BCc}$ & $19,5 \mathrm{Bc}$ & $53,0 \mathrm{Ab}$ \\
\hline 50 & $52,5 \mathrm{Ca}$ & $60,0 \mathrm{BCc}$ & $92,0 \mathrm{Aa}$ & $77,0 \mathrm{Aa}$ \\
\hline 60 & $67,0 \mathrm{ABa}$ & $78,0 \mathrm{Aa}$ & $60,5 \mathrm{ABb}$ & $57,0 \mathrm{Bb}$ \\
\hline \multicolumn{5}{|l|}{ C.V. $(\%)=19,77$} \\
\hline \multicolumn{5}{|c|}{ Envelhecimento acelerado (\%) } \\
\hline 40 & $0,0 \mathrm{Cb}$ & $11,5 \mathrm{Cb}$ & $58,0 \mathrm{Bb}$ & $98,0 \mathrm{Aa}$ \\
\hline 50 & $86,0 \mathrm{Aa}$ & $85,0 \mathrm{Ba}$ & $84,0 \mathrm{ABa}$ & $72,5 \mathrm{Bb}$ \\
\hline 60 & $87,0 \mathrm{Aa}$ & $86,0 \mathrm{Aa}$ & $80,5 \mathrm{Aa}$ & $60,5 \mathrm{Bc}$ \\
\hline \multicolumn{5}{|l|}{ C.V. $(\%)=9,43$} \\
\hline & \multicolumn{4}{|c|}{ IVE } \\
\hline 40 & $0,00 \mathrm{Cb}$ & $0,26 \mathrm{Cb}$ & $1,36 \mathrm{Bb}$ & $2,64 \mathrm{Aa}$ \\
\hline 50 & $2,01 \mathrm{Ba}$ & $2,06 \mathrm{Ba}$ & $2,65 \mathrm{Aa}$ & $2,39 \mathrm{Aab}$ \\
\hline 60 & $2,28 \mathrm{Aa}$ & $2,15 \mathrm{Aa}$ & $2,38 \mathrm{Ab}$ & $2,27 \mathrm{Ab}$ \\
\hline \multicolumn{5}{|l|}{ C.V. $(\%)=8,88$} \\
\hline & \multicolumn{4}{|c|}{ Condutividade elétrica $\left(\mu \mathrm{S} \mathrm{cm}^{-1} \cdot \mathrm{g}^{-1}\right.$ de sementes $)$} \\
\hline 40 & $580,75 \mathrm{Aa}$ & $571,75 \mathrm{Aa}$ & $252,50 \mathrm{Ba}$ & $266,75 \mathrm{Ba}$ \\
\hline 50 & $141,00 \mathrm{Ab}$ & $69,50 \mathrm{Cb}$ & $140,25 \mathrm{Ab}$ & $111,75 \mathrm{Bb}$ \\
\hline 60 & $75,55 \mathrm{Ac}$ & $69,00 \mathrm{Ab}$ & $60,50 \mathrm{Ac}$ & $65,50 \mathrm{Ac}$ \\
\hline
\end{tabular}

Médias seguidas da mesma letra, maiúscula na linha e minúscula na coluna, não diferem entre si, pelo teste de Tukey a 5\% de probabilidade.

germinação foi máxima apenas quando submetidos ao armazenamento pós-colheita por 12 dias.

Pela primeira contagem de germinação e índice de velocidade de emergência (IVE), quando não foi feito o armazenamento dos frutos, houve melhor desempenho para as sementes obtidas de frutos colhidos aos 50 e 60 DAA em relação aos de 40 DAA (Tabela 2). O armazenamento dos frutos por quatro dias contribuiu para elevar o vigor das sementes quando a colheita foi feita aos 60 DAA. Por outro lado, em geral, os maiores períodos de armazenamento (8 e 12 dias) foram benéficos para o desempenho das sementes quando a colheita foi realizada aos 50 DAA. Com relação à idade dos frutos, observa-se que aos 40 DAA houve praticamente ausência de germinação com 0 e 4 dias de armazenamento, aumentando significativamente até os 12 dias. Quando os frutos foram colhidos aos 50 DAA, a qualidade das sementes foi crescente até o oitavo dia de armazenamento pós-colheita, enquanto que para os frutos colhidos aos 60 DAA houve tendência de redução do vigor, avaliado pela primeira contagem de germinação, das sementes obtidas de frutos armazenados por 12 dias, cujo desempenho foi inferior ao verificado no período de 4 dias. Em sementes de abóbora italiana, o armazenamento por 9 dias de frutos colhidos aos 55, 65 e 75 DAA foi benéfico ao vigor, avaliado pela primeira contagem de germinação (Alvarenga et al., 1991). Segundo Barbedo et al. (1994b), pelo índice de velocidade de emergência foi possível detectar pequenas diferenças existentes na qualidade fisiológica das sementes de pepino de frutos colhidos entre 15 e 45 DAA e não submetidos ao armazenamento. Por outro lado, Valdes e Gray (1998), ao colherem frutos de tomate com diferentes idades, mas sem submetê-los ao armazenamento pós-colheita, observaram que o tempo médio de germinação das sementes diferiu significativamente entre os estádios de maturação do fruto, sendo maior nas sementes 
menos maduras e decrescendo com decorrer da maturação.

Pelo teste de envelhecimento acelerado (Tabela 2), verifica-se que quando a colheita foi realizada aos 40 DAA houve comportamento semelhante ao observado nos testes de germinação, primeira contagem e IVE, ocorrendo aumento gradativo da qualidade das sementes com o aumento do período de armazenamento pós-colheita dos frutos. Já para as colheitas realizadas aos 50 e 60 DAA, em geral, o armazenamento dos frutos não foi benéfico ao vigor das sementes, sendo observado menor vigor para as sementes obtidas de frutos armazenados por 12 dias. É importante ressaltar que a germinação das sementes colhidas aos 50 DAA permaneceu alta mesmo com 12 dias de armazenamento póscolheita dos frutos (Tabela 2).

Em geral, observa-se alto vigor para as sementes extraídas de frutos com idade de 50 e 60 DAA, logo após a colheita, não havendo necessidade de armazenamento para a melhoria do vigor, ao contrário do que foi constatado por Alvarenga et al. (1991) para sementes de abobrinha italiana. No entanto, para a expressão da capacidade máxima de germinação (Tabela 2) dos frutos colhidos com 50 DAA, estes devem ser mantidos armazenados por até 8 dias, pois apesar deste tratamento não ter diferido significativamente do tratamento sem armazenamento, a germinação foi de $84 \%$ (sem armazenamento) contra $100 \%$ com 8 dias de armazenamento pós-colheita. Estes resultados concordam com aqueles obtidos por Sanchez et al. (1993) em sementes de pimentão, onde o armazenamento por 14 dias de frutos colhidos aos 30 DAA promoveu acréscimos significativos na germinação. Estes autores verificaram que mesmo em frutos colhidos maduros (50 DAA), já com coloração vermelha, a permanência das sementes dentro do fruto, por períodos de até 28 dias, foi benéfica à germinação.

Elevados valores de condutividade elétrica (Tabela 2) foram obtidos para as sementes de frutos colhidos aos 40 DAA e submetidos a 0 e 4 dias de armazenamento pós-colheita. Com o armazenamento dos frutos por 8 e 12 dias, houve redução significativa condutividade elétrica, indicando que este procedimento favoreceu à estruturação do sistema de membranas, com conseqüente melhoria do vigor destas sementes. Quando a colheita foi realizada aos 50 DAA, menor vigor foi observado para as sementes de frutos submetidos a 0 e 8 dias de armazenamento; frutos armazenados por 12 dias produziram sementes de vigor intermediário, enquanto que sementes de maior vigor foram obtidas de frutos armazenados por 4 dias.

Os valores de condutividade elétrica observados para as sementes extraídas de frutos com idade de 60 DAA foram semelhantes, independentemente do período de armazenamento, indicando que as membranas celulares já se encontravam satisfatoriamente organizadas por ocasião da colheita dos frutos. Assim, para esta época de colheita, o armazenamento pós-colheita dos frutos não promoveu aumento significativo no vigor das sementes, o que também foi constatado pelos resultados de germinação, envelhecimento acelerado e índice de velocidade emergência. Apenas pela primeira contagem de germinação é que o armazenamento por 4 dias, para os frutos colhidos aos $60 \mathrm{DAA}$, foi benéfico ao desempenho das sementes, apesar de não ter diferido significativamente dos períodos de 0 e 8 dias. Demir e Ellis (1992) verificam maiores valores de condutividade elétrica, ou seja, menor vigor, para sementes de tomate colhidas aos 75 DAA quando comparadas com as obtidas de colheitas feitas aos 45, 55 e 65 DAA, observaram ainda que os menores valores de condutividade elétrica coincidiram com os valores máximos de germinação, não estando relacionados a maior rapidez de germinação.

Comparando os resultados do conteúdo de matéria seca das sementes (Tabela 1) com os de vigor (Figura 2), verificase que aos 40 DAA o aumento significativo no conteúdo de matéria seca promovido pelo armazenamento dos frutos refletiu em aumento no vigor das sementes, independente do teste de vigor utilizado, obtendo-se valores máximos para ambas as características, nos frutos armazenados por 12 dias. Por outro lado, para a colheita realizada aos 50 DAA, o maior conteúdo de matéria seca das sementes esteve associado ao maior vigor, quando este foi avaliado pela primeira contagem de germinação e IVE (Tabela 2). Aos 60 DAA, maior conteúdo de matéria seca (Tabela 1) foi verificado nas sementes obtidas de frutos não armazenados, o que não implicou em maior vigor destas sementes em relação às dos demais tratamentos. Assim, para as colheitas mais tardias, o maior conteúdo de matéria seca acumulado pelas sementes não apresentou reflexos positivos no desempenho das sementes, o que só foi comprovado quando os frutos foram colhidos mais jovens (40 DAA). Demir e Ellis (1992) verificaram que sementes de tomate colhidas aos 70 DAA apresentaram máxima germinação e emergência de plântulas e que a qualidade máxima das sementes não se mostrou relacionada ao seu conteúdo máximo de matéria seca. Resultados semelhantes foram obtidos por Alvarenga et al. (1991) com sementes de abóbora italiana.

Analisando-se todas as características estudadas, podese notar que sementes colhidas aos 60 DAA tiveram qualidade fisiológica máxima logo após a colheita, não sendo benéfico 
o armazenamento pós-colheita dos frutos. Já na colheita realizada aos 50 DAA, o armazenamento dos frutos por 8 dias elevou significativamente a velocidade de germinação das sementes, conforme se verifica nos resultados de primeira contagem de germinação e velocidade de emergência das plântulas, não afetando as demais características avaliadas (Tabela 2). Entretanto, sementes de elevada qualidade fisiológica também foram obtidas na colheita precoce (40 DAA), quando os frutos apresentavam coloração externa transitória do verde ao vermelho, desde que associada a um período de armazenamento pós-colheita dos frutos de 12 dias. Este é um aspecto interessante, pois permite que menor número de colheitas seja realizado, colhendo-se frutos em diferentes estádios de maturação, extraindo-se as sementes dos frutos maduros e submetendo-se os demais a períodos variáveis de armazenamento pós-colheita, para a completa maturação da semente e expressão de seu potencial máximo de qualidade.

\section{CONCLUSÕES}

O armazenamento pós-colheita dos frutos de tomate por 12 dias é benéfico à qualidade fisiológica das sementes apenas quando a colheita é realizada aos $40 \mathrm{DAA}$, estando os frutos com coloração externa transitória do verde ao vermelho.

Sementes de elevada qualidade são obtidas de frutos colhidos aos 50 e 60 DAA e não armazenados.

\section{REFERÊNCIAS}

ALVARENGA, E.M.; SILVA, R.F.; ARAÚJO, E.F.; CARDOSO, A.A. Influência da idade e armazenamento pós-colheita dos frutos na qualidade de sementes de melancia. Horticultura Brasileira, Brasília, v.2, n.2, p.5-8, 1984.

ALVARENGA, E.M.; SILVA, R.F.; ARAÚJO, E.F.; LEIRO, L.S. Maturação fisiológica de sementes de abóbora italiana. Revista Brasileira de Sementes, Brasília, v.13, n.2, p.147-150, 1991.

ARAÚJO, E.F.; MANTOVANI, E.C., SILVA, R.F. Influência da idade e armazenamento dos frutos na qualidade de sementes de abóbora. Revista Brasileira de Sementes, Brasília, v.4, n.1, p.77-87, 1982.

BARBEDO, C.; COELHO, A.S.; ZANIN, A.C.; NAKAGAWA, J. Influência da idade do fruto na qualidade de sementes de pepino. Horticultura Brasileira, Brasília, v.11, n.1, p.18-21, 1993.

BARBEDO, A.S.C.; ZANIN, A.C.W.; BARBEDO, C.J.; NAKAGAWA, J. Efeitos da idade e do período de repouso póscolheita dos frutos sobre a qualidade de sementes de berinjela.
Horticultura Brasileira, Brasília, v.12, n.1, p.18-21, 1994a.

BARBEDO, C.J.; NAKAGAWA, J.; BARBEDO, A.S.C.; ZANIN, A.C.W. Influência da idade e do período de repouso pós-colheita de frutos de pepino cv, Rubi na qualidade fisiológica de sementes. Horticultura Brasileira, Brasília, v.12, n.2, p.14-18, 1994 b.

BERRY, T.; BEWLEY, J.D. Seeds of tomato (Lycopersicon esculentum Mill.) which develop in a fully hydrated environment in the fruit switch from a developmental to a germinative mode whitout a requeriment for dessication. Planta, Berlim, v.186, n.1, p.27-34, 1991.

BRASIL. Ministério da Agricultura e Reforma Agrária. Regras para análise de sementes. Brasília: SNDA/DNDV/CLAV, 1992. $365 \mathrm{p}$.

CARVAlho, N.M.; NAKAGAWA, J. Sementes: ciência, tecnologia e produção. 4. ed. Jaboticabal: Funep, 2000. 588p.

DEMIR, I.; ELLIS, R.H. Changes in seed quality during seed development and maturation in tomato. Seed Science Research, Wallingford, v.2, n.2, p.81-87, 1992.

FONTES, P.C.R. Olericultura teoria e prática. Viçosa: Suprema, 2005. 486p.

KWON, O.S.; BRADFORD, K.J. Tomato seed development and quality as influenced by preharvest treatment with ethephon. HortScience, Alexandria, v.22, n.3, p.588-591, 1987.

MAGUIRE, J.D. Speeds of germination-aid selection and evaluation for seedling emergence and vigor. Crop Science, Madison, v.2, p.176-177, 1962.

NAKAGAWA, J. Teste de vigor baseados no desempenho das plântulas. In: KRZYZANOWSKI, F.C.; VIEIRA, R, D.; FRANÇA NETO, J.B. (Ed.) Vigor de sementes: conceito e testes. Londrina: ABRATES, 1999. cap.2. p.2.1 - 2.21.

PANOBIANCO, M. Avaliação do potencial fisiológico de sementes de tomate. 2000. 152f. Tese (Doutorado em Agronomia) - Escola Superior de Agricultura "Luiz de Queiroz", Universidade de São Paulo, Piracicaba, 2000.

PEREIRA, F.P. Produção e qualidade de semente de tomate em função do estádio de maturação do fruto e da ordem de frutificação na planta. 2004. 101f. Dissertação (Mestrado em Fitotecnia) Universidade Federal de Viçosa, Viçosa, 2004.

SANCHEZ, V.M.; SUNDSTROM, G.N.; McCLURE, G.N.; LANG, N.S. Fruit maturity, storage and postharvest maturation treatments affect bell pepper (Capsicum annuum L.) seed quality. Scientia Horticulturae, Alexandria, v.54, n.3, p.191-201, 1993.

VALDES, V.M.; GRAY, D. The influence of stage of fruit maturation on seed quality in tomato (Lycopersicon lycopersicum (L.) Karsten). Seed Science and Technology, Zürich, v.26, n.2, p.309318, 1998.

WELBAUM, G.E.; BRADFORD, K.J. Water relations of seed development and germination in muskmelon (Cucumis melo L.) VI. Influence of priming on germination responses to temperature and water potential during development. Journal of Experimental Botany, Oxford, v.42, n.236, p.393-399, 1991.

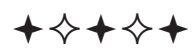

